International Journal of Engineering \& Technology, $7(2.13)(2018) 24-29$
SPC
International Journal of Engineering \& Technology
Website: $w w w . s c i e n c e p u b c o . c o m / i n d e x . p h p / I J E T$
Research Paper

\title{
Educational research networks principles of organization.
}

\author{
Nataliia N. Davydova ${ }^{1 *}$, Evgeniy M. Dorozhkin ${ }^{2}$, Vladimir A. Fedorov ${ }^{3}$ \\ ${ }^{1}$ Associate Professor of Russian State Vocational Pedagogical University, Ekaterinburg, Russia \\ ${ }^{2}$ Doctor of Pedagogical Sciences, Professor, Academician of the International Academy of Pedagogical Education, Rector of Russian \\ State Vocational Pedagogical University, Yekaterinburg, Russia \\ ${ }^{3}$ Doctor of Education, Professor of Russian State Vocational-Pedagogical University, Ekaterinburg, Russia \\ *Corresponding author E-mail: edscience@mail.ru
}

\begin{abstract}
Relevance. Modern society has global transformations; as a result, the level characteristics of its system development are changing, new opportunities and new situations to implement a self-organizing system to solve problems of self-government appear. Thus, there is the need to organize the multiplicity of interactions in the new environment, including education. The success of the development mechanisms, organizing innovative activities in the educational systems of different levels is largely determined by the active development of interaction network forms and interaction effective management. The article is devoted to development of theoretical ideas about the processes of network interaction in education to justify and describe the principles of modern scientific-educational network on the basis of systemsynergetic approach. A leading approach to study this problem can be considered as system-synergetic which allows studying network interaction within the scientific and educational network as a holistic entity consisting of interrelated elements, structured and complex. The results of the study showed that described principles of effective networking and the conditions of scientific and educational networks development allow you to combine and re-combine the accumulated actors of this knowledge and practical experience interaction, turning them into the means of its innovative activities. The article can be useful to heads of educational institutions of different levels, as well as researchers of innovative processes development problems in education.
\end{abstract}

Keywords: Anthroposenirgism; Self-Developing and Self-Organizing Educational System; Systematic and Synergetic Approach; Research and Education Network; Network Interaction.

\section{Introduction}

Innovative society. At the turn of the millennia we have become participants in the fourth global scientific revolution, which gave birth, as B. C. Stepina told, post-neoclassical science [1]. This stage of scientific research development is characterized by the intensive application of scientific knowledge in all spheres of social life. The research activities nature is changing, which is determined by the revolution in the means of storing and retrieving knowledge. Along with disciplinary-governmental research interdisciplinary and problem-oriented forms of research activity increasingly put forward to the fore. It should be noted that post-neoclassical science is well correlated with the culture of postmodernism, which is known, is the ideology of constant renewal. The postmodernism paradigm is the dynamic stability, stability through movement and the development, climbing to new levels of organization. In this regard, the trend of rethinking sources of national well-being is brightly starting to appear: from natural resources, physical labor and financial capital to maximum inclusion of high technologies and intellectual potential. The consequence of these processes is the need for improvement, reformation and/or modernization of national education systems.

In the new economic structure and social modernization there is a need in man, capable to self-actualizing, creative work, self-education, self-development, self-government, continuing education in the workplace, searching, processing, accumulating, and implicating new professional knowledge, conducting team and personal activity, able to combine personal motivation and public. To achieve this goal, we need systemic change, associated with the formation in the educational systems different levels of readiness for innovative activity that is impossible without changing the fundamentals of its development management.

\section{Review}

Today, research, different in their philosophical bases, increasingly heard the argument that "it is impossible to consider education as an appendage of the functions to produce skilled work force or to judge someone's success by the number of children and adults, received knowledge... If education is considered a human right, because it leads to the development of creative abilities, enhance participation in economic, social and cultural relations in society and, consequently, to more effective contribution to the development of mankind" [2].In this regard, an important feature of education is to transit from receptive-reflective approach to constructive activity in the educational process in particular and educational science in general [3].With regard to education, the analysis of the factors, contributing to the approaches, characteristics and methods change, producing scientific knowledge in this area leads to the conclusion that they are not so much changes in the educational activities, as a general direction learning ideal in this sphere.

Nowadays some authors consider a new type of scientific education scientific project and program type. Its core activities are design and programming, the main characteristic of which is that they develop, shape and create a new, not yet existing educational practices based 
on constructing projects and programs, organizing action for building missing elements to this educational practice [4], [5], [6]. This includes complex self-organizing design, which cannot be reduced simply to knowledge synthesis. The source of such knowledge is not in classical studies that are mainly real understanding and which design is possible and appropriate in a particular socio-cultural situation. This is a new type of science (and the nature of knowledge, and by way of receipt); here knowledge is simultaneous and systemically (i.e. multi-subject), technological and subjective [5]. An important direction to develop activities, designing and constructing new types of educational practice, is the use of network communication principles [6-9].

Describing the term "network interaction", it can be noted that it is one of the most commonly used in cases when we are talking about establishing relationships between different social systems or their individual components. The main features of networking are to coordinate, the lack of a single center, rigidly centralized management structure, the predominance of self-organizing structures. You should also consider that the boundaries of the network in this case is not specified, the rules of conduct elements are largely informal, and the network often created for the development and effort unity, performing large tasks. Moreover, the practice checked that the network exists only as long as it gives each participant more than he gives her

Therefore, in the most general form, network interaction can be defined as a collective distributed activity that involves a set of relations between all subjects of innovation development. In the community network structures the main resource of production become knowledge and information, and the dominant social group - those, who have knowledge [10].

In the framework of networking today is often discussed the problem field and strategic guidelines for development; fixed responsible initiatives, built special development modes (efficient use) of the generated resources.

Researchers believe that in the education system at the present time there are three main types of networks:

1) Network as a set of educational institutions that perform a public function, providing unified educational services to the population on the principles of universality and accessibility of General education.

2) The network, which caused by the variety of activities of the educational organizations because there are different educational programs and schools implement them, and the relationships between them. These networks like the

Internet, where the about certain content be respect and communication. Network that gives rise to new human relationships, called social-functional, or contact. In education

Such networks is represented by the schools, leading innovation development.

To develop the theme of this work, we were interested in network of the third type, when the network is regarded as a specially created environment of partnership and exchange of educational resources, where the consolidation of public forces interested in education development, creating knowledgeable community, socialization and disseminating the best examples of teaching practice [11-13]

\section{Methodology and research methods}

As the educational system is a complex, hierarchical structure, basic elements of which are people with different intellectual abilities, studying these systems it is necessary to apply combined methods. The synergy of social systems is an important scientific basis for the integration of systemic and synergetic approach in educational science and practice. The methodological approach, based on the ideas synthesis of consistency and synergy, today is defined as synergetic. Its essence, from the point of view [15] is that the synergistic properties of educational systems primarily due to anthropocentrism participants of education.

We agree with several researchers who consider that the phenomenon of anthropocentrism based on the manifestation of man's own individuality in any interaction within a relationship, due to the influence of internal and external participants' characteristics (moral qualities, beliefs, tastes and preferences, character, emotional, relationship, behavioral characteristics, etc.) on the management contents and results [16], [17]. System-synergetic approach has been widely used to study the process of network interaction as a whole, consisting of interrelated elements, structured and complicated [18], [19].

To solve research problems it was used the following set of research methods: 1) theoretical: the analysis of methodological, psychological, educational, economic literature; study legislative, normative and program-methodical documents in the field of education; systematic analysis; generalization; modeling; 2) empirical: studying and generalizing educational experience; a complex of sociological methods: an empirical data synthesis; observation; products and activities analysis; method of expert evaluations; experimental-research work

\section{The results of the study}

In the work, we are talking about the new direction network interaction development in the form of research and education networks. The concept of "research and education network" has a special meaning. On the one hand, the network acts as a set of prevailing interest creative teams representing various educational organizations engaged in the new scientific knowledge development (scientific component). It is known that the difference of scientific knowledge from any other is that scientific knowledge is justified and reveals a set of stable characteristics of the studying object, provides a subject definition from the point of belonging to any category, highlighting the values and principles, inherited in all phenomena and objects category. Scientific knowledge is systematically organized and has its own language, which is based on categorical apparatus of science, in our case its education. Chris Collinson and Geoff Parcell think that the knowledge inside the network distributes evenly, jointly created and used work methods, determines which methods function better than others, how and when they should be applied. Such communities "served knowledge and competence in a particular activity" [20], helping participants to develop their own professionalism to make valuable contributions in the suitable job.

Thus, scientific study leading to obtain scientific knowledge is a special process which consists of cognitive people's activity, knowledge resources, their objects and awareness. Recall that in contrast to spontaneously-empirical cognition, where knowledge is not separated from social and practical people's activities, specific scientific cognition is the cognitive activity in science exercise, not all, but properly prepared group of people, shape its implementation and development as a scientific study. Another fundamental difference between scientific knowledge and the spontaneous-empirical one is that scientific research is systematic and focused; it is aimed at solving problems that are consciously formulated as goals [21]. Therefore, the work course basis for the network cooperation development within the framework of scientific-educational network was founded the movement to learn the sphere of knowledge based on modeling and experimentation. In this regard, the main purpose of educational research in the scientific and educational network is in identifying new knowledge about educational processes and phenomena of learning and education in a specific educational organizations (EO) participating in the interaction, its distinctive characteristics (structure, action, development), objective logical connections between educational processes and phenomena. Networking allows you to convert (change, alter) knowledge, for example, combine and recombine knowledge and experience, turning them into tools of innovation.

At the same time, it is the effort to develop new knowledge about educational processes and phenomena explains the presence in the scientific-educational network the educational component aimed at increasing the methodological cultural level of the participants in network interaction. The educational component is the theoretical 
basis of the design and construction of the educational process, awareness, formulation and creative solution of educational tasks and methodological reflection that is implemented by full-time and distant learning participants, interacted theoretical-methodological bases of innovative activity in conditions of developing cooperation and actors' integration network on the principles of self-development and self-study.

The necessity to form methodological culture of working in a network collaboration teaching staff is defined by contemporary sociocultural situation, when the fast and rapidly changing modern information society requires a rapid correction of existing and developing innovative educational programs. The mastery of methodological culture allows the participants to carry out effective exploration of new areas in theory and practice education, to develop independence in learning through the formulation and solution of scientificmethodical and creative tasks in this field.

In consideration of the foregoing, it is quite appropriate, in our opinion, to include the term of "scientific-educational network" as meaningful from a methodological point of view, and consider it a key theory in developing educational network interaction. We suggest the following meaning of the term "scientific and educational network": this is a dynamic set of interconnected agents, representing scientific, educational, social, cultural institutions (their units, creative teams), as well as elements of innovation infrastructure and stakeholders, developing the educational system of an industrial enterprise, which operate on the type of virtual organization and carry out innovative projects in the field of education at a high level of goals coordination and all types integration of resources, achieved by internally generating the information space of the network and leading to the creation of the collective intellectual property in education and increase external (external) effect [22]. Perhaps the most important effect, developing scientific-educational network is the emergence of a community network in which the network interaction, ensuring the achievement of training objectives and requirements of the individual and society, increasing the efficiency and educational quality

Based on the foregoing, the main directions to cooperate within educational research networks developing are highlighted:

Educational direction as a combination of interacting entities to enhance competency of participants relevant to their own interaction issues, promoting the work of the resource centers, benchmarking associations for experience exchange and best practices replication. The research direction as the organization of temporary creative collectives, consortia of educational institutions and industrial enterprises for the implementation of specific educational projects.

Infrastructure in the use of centers for collective use of industrial enterprises equipment for needs of constituent entities of the network interaction.

Information direction, dealing with the creation and sustainable development information portal of scientific-educational network.

Thus, the research and education network can be regarded as a specially created extension form for participants' innovative cultura and educational space of network interaction, which worked out new types of activities and relationships forms, the exchange of educational resources to ensure the integrity, openness and ability of participants' self-development in network interaction and to create new intellectual products. The primary functional purpose of the scientific-educational network is to create a set of conditions and mechanisms to enable subjects' self-organization and self-development in innovation activities.

In fact, we are talking about a new approach to managing development of the educational, scientific organizations and enterprises, interested in educational developing, getting and promoting specific innovations $[23,24]$.This paradigm of management is considering a private educational organization and the local network structure as open self-organizing system with emergent properties (that is new, unique properties of the system are not inherent to its elements). To control such systems there requires knowledge and correct application of the principles of synergetics in the interest of the productive development of the actors' self-organization potential, allowing them the ability to continuous self-renewal and self-government for their own development.

The main conditions to form and develop an effective cooperative network in the scientific and education network should include:

1) Awareness about each participant networking uniqueness.

2) The presence of his pronounced educational subjectivity.

3) The network interaction participants' willingness to describe and present its subjective content.

4) Willingness to do the work on self-subjectivity presentation.

5) The self-presentation network adequacy of each participant and the ability to express his or her own uniqueness.

6) The technical connectivity availability, the navigation system availability.

7) Dialogic design and joint activities construction.

Integrative network-based Association is a scientific and consulting support for project activities from the scientific organizations included in the communication network. This support relates to the formation, content and organization of education in the universe of innovative culture and manifests itself in the form of participation in the developing educational programs and development programs EO or innovative research and management projects of industrial enterprises etc. This activity was implemented through training sessions organized at the request of network members, the scientificpractical conferences of different levels, educational workshops and master classes held in off-line events, and online events, etc.

We know that sustainable online learning community should possess a number of properties that form the basis for the long-term network communication development:

- wide recognition and positive reputation of particular educational institutions among potential network members;

- the position stability of the network members in the educational space;

- constant information exchange between the innovation project partners;

- unique technology or intellectual product of a specific network entities;

- Personal ties between educational organizations [25].

We consider the network as a kind of joint organizational capital which is the basis of all other EO assets. The capital formation process is the transfer from individual knowledge to national knowledge and locks them in a corporate database in order to use widely by all members of the network. The feature of corporate knowledge is the possibility to its development in the "open coding", where knowledge from the network can be taken, improved and returned onto the network. This provides not only knowledge storage in the network, but their self-development [26], [27].

Highlighted specific features of the research and education networks allow formulating a number of Principles of its organization: The principle of conceptual unity involves the selection and approval of conceptual approaches, strategies and purposes in the converting activity of participants' network interaction. The implemented result of this principle is the emergence of common scientific terminology, basic concepts and terms as invariant component of interaction network for all subjects of scientific-educational network The principle of consistency implies this approach to the phenomena analysis when a phenomenon is considered as a system, not reducible to the sum of its parts, with its own structure and specific properties of an element, determined by its place in this structure. Consistency, in our case, is a property of split-level educational organizations in the structure of scientific-educational network.

The integrity principle characterizes the interaction between the subsystems in solving common problems by sharing of responsibilities. Integrity requires all parts cooperation into that element, which in a particular situation performs a vital role. According to the principle of integrity in the scientific-educational network it is important to specify the role of each participant in the interaction process for solving problems common to scientific and educational network, i.e. to produce a functional "division of labor" between the Structural elements.

The priority development principle of scientific-educational network aimed at the creation and saturation of a single information 
educational environment in terms of identifying the main trends to develop educational sphere and possible socio-economic and cultural - educational context.

The openness principle implies increased active partnerships of educational institutions and scientific-educational network with the public, various public institutions, enterprises and organizations, with different government departments (institutions of culture, science, services, employment, social protection, etc.). The principle requires taking into account and reacting to changes in the economy, the state and education policy. It facilitates the transition in the implementation of the educational process from the old paradigm of education "description - directed - action" to a new "plan project - implementation», from the individual positions of the participants' interaction to the team, which is important for the innovation process and organized on the basis of the network interaction of its subjects to form a collective subject.

The cultivation principle is aimed at implementing the following strategies: detection in individual and collective experience of possible future samples in activities and future types of relations between the interaction terms and their gradual distribution in the whole network interaction. To implement the principle, you should have gained the culture of using theoretical knowledge in real situations with adequate educational self-determination among teachers and students.
The information sufficiency principle involves the creation of a common information space that provides an opportunity to provide information about their activities to other network members, information about activities of other network members in the global network Internet sites, creating their own channels of information, becoming part of other information channels.

The completeness principle of the innovation cycle focused on the implementation of all stages in the innovation cycle developing and implementing specific projects in the framework of scientific and educational networks. In our study, this principle is considered in developing the graph of the process development and implementation of innovations in the scientific and educational network (Fig. 1), which describes the Comprehensive nature of the temporary creative team work within the network on specific projects. We should note that the actual innovation activity in a self-organizing educational system (block 9) requires additional investment (unit 10) and the specific innovation and investment activities (blocks 11 and 12). An important part of the process to implement innovations and control self-organized educational systems of educational institutions in terms of network interactions is to assess socio-economic efficiency (block 13) and forming its own policy in respect of the proposed innovation (subsequent blocks)

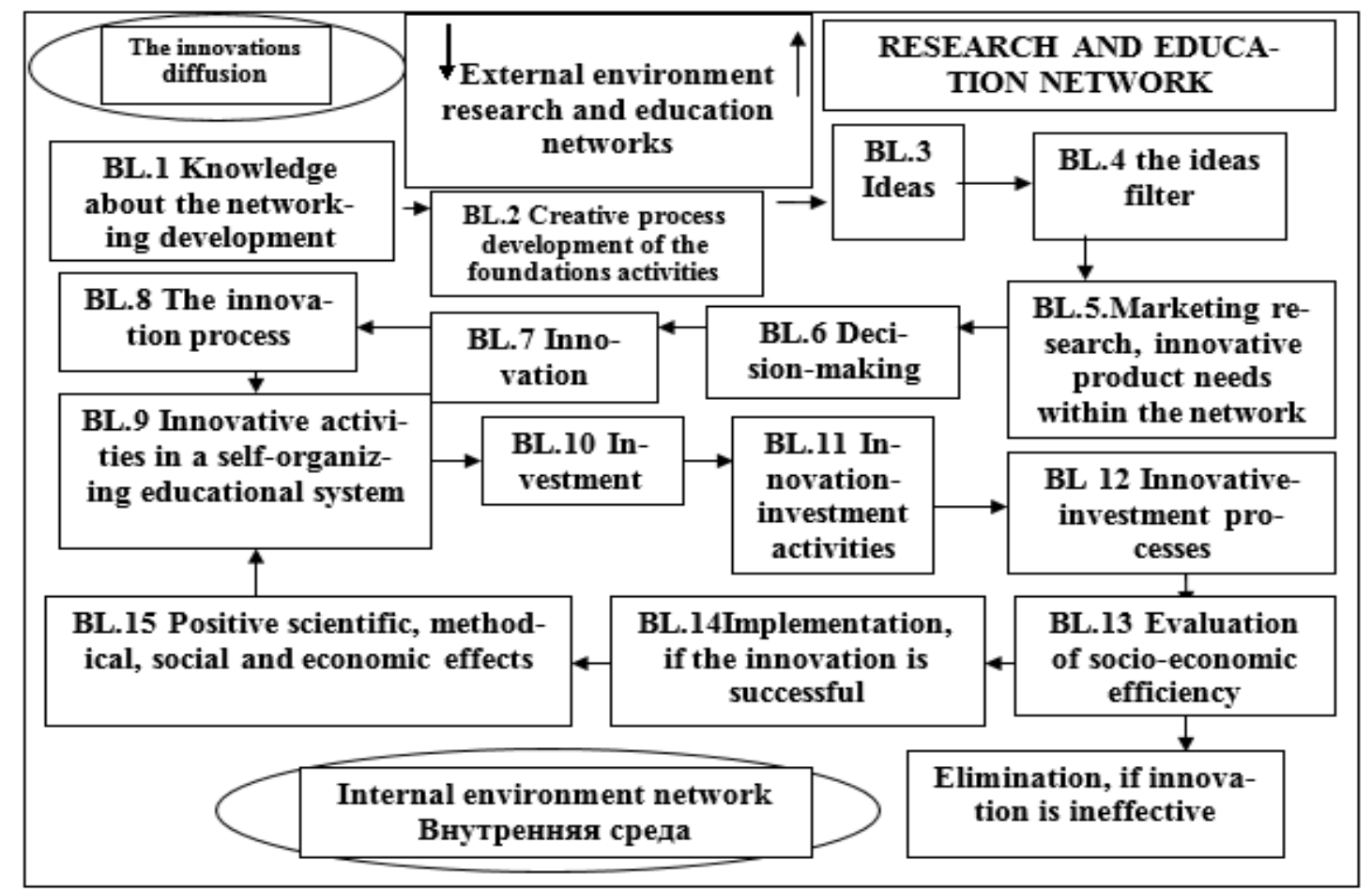

Fig. 1: The Process Graph of Innovations Development and Implementation in Terms of Self-Organizing Educational Organizations Activities of Research and Education Networks.

Implementing the integration principle of different resources types in the network interaction, it related to the establishment of relations based on mutual interests, providing intellectual products to each other and exchanging resources (information, methodological, human, etc.) to self-development, the development of general innovation environment, improving the efficiency and quality of education. On the one hand, each party has access to all of its combined resources, strengthening, thus, their own capabilities, and on the other hand ensures the development of innovative educational environment of scientific-educational network in general.

The aspect of cooperation is reflected in participation and distributed responsibility in collectively distributed activities to achieve the goals of innovative development. Organizing such cooperation, there is a positive climate; the opinion of each participant is highly valued. Members share a resource, the significance of which is not initially given, but is determined in the exchange process; in this regard, moral support is an important resource in decision making within the innovation process. The historical experience of cooperation development implementing the principle of resources integration in various fields of education has showed that it is possible: [28], [29], [30].

- Networking for professional development of educational staff;

- Rapid exchange of information, ideas and plans on interesting for participants questions, collaborative projects, broaden their horizons, raising their cultural level;

- Building interactive partners of information and communication skills, communication standards;

- Developing interactive forms of learning, interaction, information technology.

The main conditions for the performance of network communication in the framework of the scientific-educational network, consider the following: 
- $\quad$ integration of education, science and production on the basis of network interaction, which contributes to the development of strategies for the development of scientific and educational networks;

- $\quad$ organizing internal monitoring of the accumulated potential in the training field of professional staff, designing and implementing innovative projects;

- $\quad$ building politics and culture interaction between the subjects of scientific and educational networks, supported and accepted by all participants of the interaction;

- involving everyone, who is interested in the interacting developing process pure scientific and educational network;

- dissemination of best practices with the aim to develop practical recommendations, building local network structures and their effective functioning;

- the creation and development of information and communication systems to ensure timely information updating, monitoring participants' interaction in order to ensure its effectiveness;

The main result of the scientific work and educational network will be to provide subjects' self-organization and self-development in networking, creating collective intellectual property products.

The ability to provide certain competitive advantages for the participants in networking through knowledge and the possibility of direct, unlimited, virtual contacts is confirmed by the activities results of real network in innovation-active educational institutions Founded by the Russian Academy of Education "The Ural branch" growing today, Russian state professional educational University scientific research and educational network since 2006 and currently involves institutions in the system of General and professional education and interested in developing education of an industrial enterprise. It's kind of a "hollow corporation" or quasi-organization that is not cancelling deterministic real connections and relationships, but offers a new version of the virtual organization, which contribute to the transition to a state and create prospects, denying unjustified hierarchy, centralization, etc. It is known that in such virtual organizations collective intelligent systems are widely represented, where one of the most important strategic factors is intellectual, creative work, leading to a radical competitive advantage. In the case of scientific-educational network they are achieved by optimizing the organization system of educational services on the basis of agreed ideas about the content of the educational process and come through culture of trust.

\section{Discussion}

Manuel Castells noted that in the information age the dominant processes and functions are increasingly organized on the basis of networks. Networks constitute the new social morphology of our societies, but spreading the network logic significantly affects the progress and the results of the processes associated with the production, daily life, culture and power [31].One of the conditions for network interactions can be considered integration processes, increasingly acting as a response to the challenges in modern society and the educational system in different forms and at different levels. Thus, A. Giddens considers integration as the exchange, streamlined communication, reciprocity of practices between individuals or team players of innovative development. In his opinion, system integration is concerned with interaction between individual or collective subjects in the extended space-time intervals [32].

Researchers of social organizations have noted that integration carries with it two major advantages: first, the ability to enhance specialization and, simultaneously, the integration of the vital functions of the merging components and thus enhance the viability of the system as a whole; the second is the possibility of cross - compensation of resource losses or deficits due to the formation of an effective system of communication and exchange. Interaction, the pooling of resources are vital not only for development, but in some cases for mere survival of the individual educational institutions. These circumstances are set the degree of integration, leading to different results - formation of common educational space and that is especially important in the context of the study, the emergence of the educational complexes, the emergence and development of network interaction.

The creation and development of network interaction in education is largely due to the desire of educational institutions to self-development and self-organization .It is known that the emergence of the new one is possible where provided great opportunity, where there is freedom to choose. In particular, in education, the excess diversity creates a spectrum of possible directions to develop particular educational systems, provides material to select the optimal trends of this development. For education to be able to social engineering, cultural education, not just the transmission of knowledge and norms, the processes of educational systems development should encourage educational organizations to self-development and selforganization. We should note, that if the self-development process characterizes the target object, changing within the time under the influence of its internal, immanent causes (causa sui), self-organizing characterizes the structural mechanism, the object internal structure complexity the due to the interactions between its elements [33], [34], [35].

The need to develop corporate processes stimulates the transition to enhanced cooperation open educational systems in terms of networking. Speaking about the use of the term "network" in modern social knowledge, it should be noted that it has many dimensions and levels of reflection. Discusses network theory, network approach, network communities, network culture and virtual social networks, inter-firm and institutional networks of knowledge, etc. Today the main features of knowledge networks have become the multi-dimensionality and layering of this region, a variety of methodological principles for their development [36].

At the same time, a growing desire to formalize knowledge about networks, creating a unified of network theory with all the expected attributes of strict scientific knowledge $[37,38,39]$. Therefore, the multidimensionality and diversity of ideas about networks in modern social knowledge updated questions not only about the term "network" but also about perspective the development of this research area [40] ,[41], [42],[143], [44]. It should be understood that the art of creating a network is an art to adhesively bind together the heterogeneous elements included in its composition.

\section{Conclusion}

Thus, the basis for the networking subjects' development within the scientific and educational network founded the movement to the knowledge in the selected knowledge-based process modeling and experimentation. By themselves the organizing principles and conditions for scientific-educational networks development allow to combine and recombine knowledge and practical experience, transforming them into effective activation means of participants' innovative activity. In the course of scientific-educational network the integration of education, science and production on the basis of network interaction is achieved, which contributes to design specific development strategies of constituent network entities due to the formation of supported and accepted by all participants of the politics, cultural interaction and involvement in the network development process and best practices dissemination in order to develop practical recommendations for effective functioning. The main result of scientific and educational the network will be to provide subjects 'self-organizing and self-development in networking, building collective intellectual property products. 


\section{References}

[1] Stepin V. S. (2004) The Problem of types of civilizational development, Moscow: Izd vo ROS. Acad. public service, 2004. 36 p.

[2] Allak, J. (1993) a contribution to the future: the priority of education. Moscow: Pedagogika-Press, 164 p.: 17

[3] Vasilkov. V. (1999) Order and chaos in development of social systems: Synergetics and theory of social self-organization. Saint-Petersburg: LAN', 1999. 480 p.: 33 p.

[4] Gromyko Y. V. (1996). Design and programming of educational development. Moscow: MARO, 1996. 545 p.

[5] Davydov V. (1996). The theory of developmental education. Moscow: Intor, $544 \mathrm{p}$.

[6] Slobodchikov. V. I. (2009) an anthropological perspective of national education. Ekaterinburg: Izd. Ekaterinbourgskoj Eparkhii, 264 p.

[7] Babanskij U. K. (1982) Problems of increase of efficiency of pedagogical research. Moscow: Pedagogika, 1982. $191 \mathrm{p}$.

[8] Ininisin. M. A. A. Dagaev A. A, (2007) Innovation management: concepts, multilevel strategy and mechanisms of innovative development: Moscow: Business, 2007. 584 p.

[9] Davydova N.N. (2010). Organizational and managerial model of interaction of educational institutions as a factor of innovation development of regional education. The Education and science journal. No. 8. p. $32-42$

[10] Hassling R. (2003), the Contexts and perspectives of network theory. [Electronic resource]: Social processes as a network game. Sociological essays on the main aspects of network theory. Moscow: LogosAl'tera. Mode of access: http://www.cyberpolitics.ru/ content/view/272/34/.

[11] Adamski, A. I., (2002). The model of network interaction [Electronic resource]: school Governance. No. 4. P. 23-24. Mode of access: http://upr.1september.rU/2002/04/2.htm.

[12] Gromyko Y. V. (2000). Critical-thinking pedagogy (theoretical and practical guide to the development of higher specimens of pedagogical art) Minsk, Tekhnoprint, 2000. 376 p.

[13] Davydova N.N. (2012) Formation of system of management of innovative activity of institutions of the modern scientific-educational network. Scientific-Information Journal "Management Issues". No. 1, pp. 98-105

[14] Churchill E., Girgesohn A., Nelson L., Lee A. (2004). Building Digital and Physical Spaces for Ubiquitous Community Participation. Communications of the ACM. 2004. Vol. 47, № 2. p. 39-44.

[15] Coogan, B. A., Serikov G. N. (2002). The Management of the educational system: the interaction of actors in the regional and municipal level. M.: Vlados, 2002, 632 p

[16] Serikov G. N. (1997) Education: aspects of systemic reflection. Kurgan: Zaural'e, 1997.

[17] Chesbrough H. W. (2003) Open Innovation: The New Imperative for Creating and Profiting from Technology. Cambridge, MA: Harvard Business School Publishing, 2003. 82 p.

[18] Gapontsev.V.L., Fedorov V.A., Gaponceva M. G. (2008) Synergy in teaching: the appropriateness of the transfer. The Education and science journal. No. 9. p. 100-110.

[19] Iskrin N.S., Chichkanova T.A.(2015) The systematic approach to management in education. The Education and science journal. 2015 one 7-21. DOI: 10.17853/1994-5639-2015-1-7-21.

[20] Collinson C., Parsell G. (2006) Learning to fly. Lessons learned on knowledge management from the best scientific organizations. Moscow: Institut kompleksnykh strategicheskikh issledovaniy, 2006, $296 \mathrm{p}$

[21] Krajewski. V. (2001) Methodology of pedagogical research. Cheboksary: publishing house of the Chuvash. UN-TA, 2001. $244 \mathrm{p}$.

[22] Davydova N.N. (2013). Implementing the systematic synergetic approach in management practices related to the research and education network development. The Education and science journal. 7: 67-85. DOI: 10.17853/1994-5639-2013-7-67-85

[23] Davydova N.N., Dorozhkin E.M. (2016). Management of a Network Interaction of Educational Organizations Oriented to Innovation Development. Indian Journal of Science and Technology, Vol 9 (29), DOI: $\quad 10.17485 / \mathrm{ijst} / 2016 / \mathrm{v} 9 \mathrm{i} 29 / 88729, \quad$ August 2016 http://www.indjst.org/index.php/indjst/article/view/88729/72065.

[24] Davydova N.N. (2013) Formation of innovation policy of educational organizations in the framework of scientific and educational networks. Scientific-Information Journal "Management Issues". 2013. No. 6. p. $240-246$

[25] Davydova N.N., Fedorov V.A., (2013) Modeling development of educational institutions on the basis of a network approach. Pedagogika, No. 6, p. 49 - 54
[26] Davydova N.N., Fedorov, V.A (2012) Managing the development of educational institutions on the basis of a network approach. Pedagogical journal of Bashkortostan, 2012. No. 4. p. 15-23.

[27] Davydova, N.N., Dorozhkin, E.M., Polyanskova, N.V. \& Nuykina, E.Y. (2016). Formation of a Cluster Integration System of Educational Institutions within the Region. International Journal of Environmental and Science Education, 11(16), 9206-9221.

[28] Davydova.N.N., Fedorov..V.A. (2013) Methodological bases of management of educational institutions in the conditions of network interaction. Kazan science. 2013. No. 9, p. 13 - 22.

[29] Davydova, N.N., Dorozhkin, E.M. \& Fedorov, V.A. (2016). Innovative process development in the framework of scientific educational network: Management model. Naukovyi Visnyk Natsionalnoho Hirnychoho Universytetu. [Bulletin of National Scientific University Mining] 5, p.157-163.

[30] Dorozhkin E. M., Davydova N.N. (2013) The Development of educational institutions in the course of networking. Higher education in Russia. No. 11. p. 11-17.

[31] Castells M, (1999). The Establishment of the society of network structures. Moscow: Academia, 1999. P. 494-505.

[32] Giddens, E. (2005) The organization of a society: outline of the theory of structural Moscow: Academic project, 2005. 528 p.: 54.

[33] Evtodieva T.E., Davydova N.N., Videneeva S.V., Fedorov V.A. (2016). The concept of network organization and design of networks in logistics. International Journal of Economic Perspectives. 2016 V. 10. № (3). http://www.econ-society.org/ijep_contents_10.3.php\#.

[34] Komarov S. V., Molodchik A.V., Pustovoit K.S. (2012) On the boundary change paradigm of management: self-developing, self-organizing system. Journal of economic theory. 2012. No. 3. p. 132 141.

[35] Komarov S. V., Cordon.And. (2005) the Basics of methodology: system diagnostics approach. Perm: Publishing house Perm in. State University the 2005, $384 \mathrm{p}$.

[36] Remorenko I. M. (2005). Different management for different education Agency educational cooperation. Saint Petersburg 2005, 368 p.

[37] Karlof B., Soderberg, S. (1996) the Challenge leaders. Moscow: Business, 1996. 352.

[38] Nowotny H., Scott P., Gibbons M. (2003). «Mode 2» Revisited: The New Production of Knowledge. Minerva. 2003. Vol. 41, № 3. P. 179-194.

[39] Vasilevskaya, E. V. (2007) Network organization of the methodical work at the municipal level. Moscow: APK of continuing education for educators $2007,65 \mathrm{p}$.

[40] Aref'eva, T. A. (2012) The Creation of a model of the gymnasium educational environment creative type. Innovative processes in education. No. 5. p. 62-69

[41] Braillard Ph., Djalili M. R. (1990) Les relations intemationales. Paris, $1990118 \mathrm{p}$.

[42] Brown J. S. (2002) The Social Life of Learning: How can Continuing Education be Recon figurate in the Future? Continuing Higher Education Review. 2002. Vol. 66. p. 50-69.

[43] Grant R., Baden-Fuller C. (2004). A Knowledge Accessing Theory of Strategic Alliances Journal of Management Studies. 41(1): 61-84 / DOI: 10.1111/j.1467-6486.2004.00421.x

[44] Makarov. I. (2009) The Philosophy of self-organization. Moscow: LIBROKOM 2009, 432 p. 